\title{
Correction to: Novel method to estimate the appropriate dosing interval for activated charcoal to avoid interaction with other drugs
}

\author{
Hisakazu Ohtani ${ }^{1}$ (D) Kota Nakamura ${ }^{1} \cdot$ Ayuko Imaoka $^{1} \cdot$ Takeshi Akiyoshi $^{1}$ \\ Published online: 16 September 2020 \\ (C) Springer-Verlag GmbH Germany, part of Springer Nature 2020
}

\section{Correction to: European Journal of Clinical Pharmacology} https://doi.org/10.1007/s00228-020-02931-y

Figure 3 image was inadvertently removed from the original article.

The original article has been corrected.

Publisher's note Springer Nature remains neutral with regard to jurisdictional claims in published maps and institutional affiliations.

The online version of the original article can be found at https://doi.org/ 10.1007/s00228-020-02931-y

Hisakazu Ohtani

ohtani-tky@umin.net

1 Division of Clinical Pharmacokinetics, Keio University Faculty of Pharmacy, 1-5-30, Shibakoen, Minato-ku, Tokyo 105-8512, Japan 